\title{
EMISSION TRADING IN EUROPE WITH AN EXCHANGE RATE
}

Ger A.J. Klaassen

International Institute for Applied Systems Analysis

Laxenburg, Austria

Finn R. Førsund

Department of Economics, University of Oslo, Norway

Markus Amann

International Institute for Applied Systems Analysis

Laxenburg, Austria

RR-95-2

January 1995

Reprinted from Environmental and Resource Economics 4:305-330, 1994.

INTERNATIONAL INSTITUTE FOR APPLIED SYSTEMS ANALYSIS

Laxenburg, Austria 
Research Reports, which record research conducted at IIASA, are independently reviewed before publication. Views or opinions expressed herein do not necessarily represent those of the Institute, its National Member Organizations, or other organizations supporting the work.

Reprinted with permission from Environmental and Resource Economics 4:305-330, 1994. Copyright @ 1994 Kluwer Academic Publishers.

All rights reserved. No part of this publication may be reproduced or transmitted in any form or by any means, electronic or mechanical, including photocopy, recording, or any information storage or retrieval system, without permission in writing from the copyright holder.

Printed by Novographic, Vienna, Austria. 


\section{Preface}

Economic instruments are considered a potentially powerful means for increasing the cost-effectiveness of strategies to improve the environment. Mechanisms such as joint implementation, trading of emission reduction obligations, emission charges, and taxes are currently the subject of much discussion. Often it is argued that such instruments could achieve substantial cost savings over alternative regulatory approaches.

IIASA's research on transboundary air pollution focuses inter alia on the question of whether such potential cost savings are achieved at the expense of environmental protection. The environmental impacts of "global" pollutants with a long atmospheric residence time, such as many greenhouse gases, are primarily determined by the total amount of emissions. However, for "regional" pollutants such as sulfur dioxide, which have a shorter life time, the location of the emissions may have a strong impact on the environmental effects.

In order to overcome such problems, it has been suggested that an "exchange rate" be introduced to determine compensatory reductions necessary to ensure that the regional impacts from sulfur deposition remain unchanged. This paper analyzes whether a trading scheme for $\mathrm{SO}_{2}$ emissions with an "exchange rate" could indeed account for the regional differences in environmental sensitivities.

Although the paper has its main emphasis on the economics of air pollution control, extensive use of other elements of IIASA's integrated assessment work, e.g., models on atmospheric dispersion characteristics or the assessment of regional environmental sensitivities, has been made.

\section{Peter E. de Jánosi \\ Director}




\title{
Emission Trading in Europe with an Exchange Rate
}

\author{
GER A.J. KLAASSEN ${ }^{1}$, FINN R. FøRSUND ${ }^{2}$ and MARKUS AMANN ${ }^{1}$ \\ ${ }^{1}$ International Institute for Applied Systems Analysis, A-2361 Laxenburg, Austria; \\ ${ }^{2}$ Department of Economics, University of Oslo, P.O. Box 1095 Blindern, N-0317 Oslo, \\ Norway
}

\begin{abstract}
This paper explores the analytical and empirical properties of a new method for emission trading according to a fixed exchange rate. The exchange rate is based on the ratios of the marginal costs of abatement in the optimal solution in order to account for the impact of the location of emission sources on the deposition. It is shown that, generally, this system will not achieve the optimal solution and does not guarantee that environmental deposition constraints are not violated, although total abatement costs are always reduced. A routine was developed to mimic trading as a bilateral, sequential process, subject to an exchange rate. In the example used, results for $\mathrm{SO}_{2}$ emissions in Europe show that, starting from a uniform reduction, exchange-rate trading achieves higher cost savings than one-to-one trading, without achieving the cost minimum. Sulfur deposition targets are not violated since the initial emission allocation overfulfilled targets at many places. The results are sensitive to: pre-trade emission levels, the transaction costs, the availability of information on potential cost savings and assumptions made on the behavior of trading partners.
\end{abstract}

Key words. Emission trading, air pollution, economic instruments, costs, europe, sulfur.

\section{Introduction}

Currently, negotiations are in progress on a new protocol to control sulfur dioxide emissions in Europe. The present protocol calls for all signatories to uniformly reduce their $\mathrm{SO}_{2}$ emissions by $30 \%$ by 1993 , in comparison to the year 1980. A major new element of the current negotiations is the intention to apply an effect-oriented approach by basing the extent of emission reductions on the susceptibility of natural ecosystems to acid deposition. This implies the setting of targets for the deposition. In Batterman and Amann (1991) and Derwent (1990) mathematical optimization procedures have been used to derive cost-minimal reduction patterns under the constraint of given deposition targets, assuming that full information on the atmospheric dispersion behavior of pollutants and emission reduction costs is available. So in principle, countries could base an agreement on the cost-minimal solution. Some countries, however, plead for more flexibility and for allowing countries to trade emission reduction commitments. Two reasons are important. Firstly, although countries might agree on implementing the cost-minimal solution, the uncertainty of cost estimates, as well as the fact that cost estimates change over time, can be put forward as arguments for allowing emission trading among countries.

Environmental and Resource Economics 4: 305-330, 1994.

(C) 1994 Kluwer Academic Publishers. Printed in the Netherlands. 
Secondly, countries might not be able to agree on the cost-minimal solution. In this case, emission trading could be used to approach the optimal solution.

A major concern in theory and practice has been the fact that sulfur dioxide deposition has different local effects and sulfur dioxide disperses nonuniformly, implying that both emission level and location of sources influence the deposition pattern. Montgomery (1972) showed that there exists a set of prices on ambient permits issued for depositions at each receptor that yields the total cost minimum. Others raised questions on the practicality of these ambient permits, in view of the large number of markets in which polluters had to operate (Tietenberg, 1985) and all revisions of prices, due to differing patterns of emissions and depositions, as trade takes place. Moreover, countries would have to obtain permits for all downwind markets, and decide on whether to buy or sell if initial permits are issued for all regional markets. When permit prices change, permit demand/supply would have to be recalculated for each regional market. Alternatives, such as pollutionoffset trading, were suggested (McGartland and Oates, 1985; Krupnick et al., 1983) which in theory are equally cost-effective. Pollution offset trading allows one source to increase its emissions as long as another source reduces its emissions in such a way that deposition or concentration standards are not violated. The increase in concentration caused by one source has to be offset by a decrease by the other source. In such a regime, sources do not trade emissions on the basis of a fixed rate, but the rate (Krupnick et al., 1983) depends on the actual emissions of all other sources and can be chosen by the trading sources. Simulation studies suggest, however, that if offset trading is simulated as a bilateral sequential process, trading might not attain the cost-minimum solution (Kruitwagen, 1992; Atkinson and Tietenberg, 1991). Practical application of emission trading, when subject to deposition rules (Borowski and Ellis, 1987), showed that, although cost savings are high, they are far from optimal (Hahn and Hester, 1989; Hahn, 1989; Tietenberg, 1990). Since dispersion models are required, this limits trading and cost savings considerably. This points to the need for simpler designs that still account for deposition goals.

The objective of this paper is to explore the properties of a new, simple system of emission trading based on a fixed exchange rate. Under this system, sources are allowed to trade on the basis of exchange rates that account for the location of the sources. More specifically, the exchange rate between two sources depends on the (shadow price) weighted sum of the transfer coefficients of the binding receptors. The paper develops and applies a method to simulate exchange-rate trading as a bilateral, sequential process.

The paper first examines the analytical properties of such an exchangerate trading. Secondly, the method and data to simulate a process of bilateral, sequential trading are described. Thirdly, some example results are given and discussed. 


\section{Cost-Effectiveness and Exchange-Rate Trading}

\subsection{COST-EFFECTIVENESS WITH NON-UNIFORMLY DISPERSED POLLUTANTS}

When modelling the transfrontier pollution problem caused by airborne pollutants such as sulfur, two types of relationships have to be known: the efficient purification cost functions for each source, and the unit transport coefficient matrix, showing the amount of a unit of emission from one source reaching all receptors in question as depositions, for all sources in turn.

A cost effective solution is achieved when desired levels of deposition at certain receptors are obtained at minimal total cost summing over source purification costs (Montgomery, 1972; Baumol and Oates, 1988): ${ }^{1}$

$\operatorname{Min} \sum_{i=1}^{n} c_{i}\left(e_{i}^{0}-e_{i}\right)$

under the constraints

$$
\begin{aligned}
& \sum_{i=1}^{n} a_{i j} e_{i} \leq \mathrm{D}_{j}^{*}+b_{j}, \quad j=1, \ldots, m \\
& e_{i} \leq e_{i}^{0}, \quad i=1, \ldots, n
\end{aligned}
$$

$e_{i}^{0}=$ initial unrestricted emission; $e_{i}=$ remaining emission (after purification), $0 \leq e_{i} \leq e_{i}^{0} ; a_{i j}=$ transport from source $i$ to receptor $j$ per unit emitted from source $i ; b_{j}=$ the exogenous background deposition at source $j$; $D_{j}^{*}=$ deposition target at receptor $j$.

A necessary condition for an interior solution is:

$$
c_{i}^{\prime}-\sum_{j=1}^{m} a_{i j} \lambda_{j}=0, \quad i=1, \ldots, n
$$

$c_{i}^{\prime}=$ marginal purification cost of source $i ; \lambda_{j}=$ shadow price on the deposition target $D_{j}^{*}$ (positive for binding receptors, zero otherwise).

The shadow prices relate to the changes in total purification costs of a marginal tightening of each deposition constraint in turn.

To improve the understanding of the optimal solution the isocost curves (on implicit form) of the total purification cost function can be introduced:

$$
\sum_{i=1}^{n} c_{i}\left(e_{i}^{0}-e_{i}\right)=\text { constant. }
$$

In the case of two sources, isocost curves can be introduced in a diagram depicting emissions from the two sources along the axes (Krupnick et al., 1983). The isocost curve in Figure 1 shows the relationship between the two emissions for a constant level of total purification costs. The picture is based on the assumption that marginal abatement costs increase when emissions decrease. The picture is drawn in such a way that combinations of emissions 


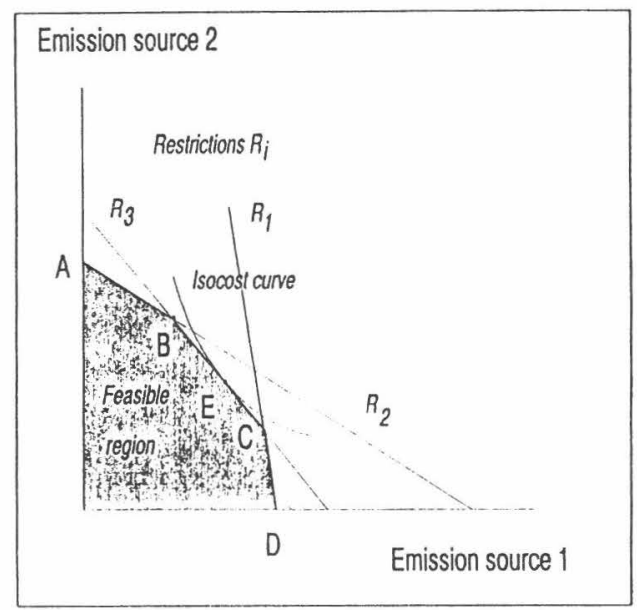

Fig. 1. The cost efficient solution.

from both sources "north-east" of the depicted iso-cost curve imply lower costs, since emission levels are higher, and hence, emissions abated and associated costs are lower. Iso-cost curves located "south-west" from the one depicted result in higher costs, since emission levels are lower. Deposition constraints can be introduced in such a diagram as straight lines, since the unit transportation coefficients are constants. Three receptors with the deposition restrictions $R_{1}, R_{2}$ and $R_{3}$ are shown. These lines show combinations of emissions from both sources that lead to depositions equal to the standards. The slopes of the lines reflect the value of the transportation coefficients in question, and they show the offset rates between emissions from the two sources.

The cost efficient solution is found at point $E$ on the line segment $B C$. In this solution, it is only the deposition target for receptor 3 that is binding. The shadow prices $\lambda_{1}$ and $\lambda_{2}$ are, accordingly, equal to zero. At the optimal point, $E$, the slope of the target load constraint that is binding, is equal to the slope of the total cost function.

\subsection{EXCHANGE-RATE TRADING}

As pointed out in the introduction, a system of issuing permits for each receptor is hardly operational. Another approach, more in line with the existing sulfur agreement, is to provide each country with a certain number of permits adding up to total allowed emissions per country. When emission permits are issued on a country basis, the resulting deposition pattern may not be the most costeffective way to meet a given set of deposition targets. In the current negotiations on a new sulfur protocol, national emission totals have been chosen so that an agreed set of targets for the deposition is met. Such targets 
can be met at minimum cost or at higher costs, using another distribution of national emission reductions that might be politically more acceptable (UNECE, 1993). Introducing trading in permits between countries, for example on a one-to-one basis, does not restore the consideration of different regional deposition constraints. One idea then is to introduce fixed exchange rates for trades reflecting the different impact of emissions. The exchange rate gives the volume of emissions one source has to decrease when another source increases its emissions with one unit. This concept differs from the concept of pollution-offset trading as described by Krupnick et al. (1983) in two respects:

- In Krupnick et al. (1983) the offset rate is not fixed, but can be selected by the trading sources as long as the deposition constraints are not violated, whereas in our proposal, the exchange rate is fixed.

- In our system there is no testing of violation of deposition constraints, but trades are allowed as long as the exchange rate is used. In Krupnick et al. (1983) only those trades are allowed that do not violate air quality standards.

The relationship between marginal purification costs at source $i$ and source $s$ at the optimal solution is:

$$
c_{s}^{\prime}=\frac{\sum_{j=1}^{m} a_{i j} \lambda_{j}}{\sum_{j=1}^{m} a_{s j} \lambda_{j}}=v .
$$

This ratio, $v$, will be called the "exchange rate" (or "trade ratio"). The marginal deposition costs in the optimum for each source differ according to variations in the transportation coefficients for the binding receptors. To explain how this exchange rate governs trading, one can imagine a simple example with one binding receptor (in the cost-minimum) and two sources. Assuming a transfer coefficient from source $i$ to the receptor of 0.5 and from source $s$ to the receptor of 1 , the exchange rate would be

$$
\frac{c_{i}^{\prime}}{c_{s}^{\prime}}=\frac{0.5 \lambda_{1}}{1 \lambda_{1}}=\frac{0.5}{1}=0.5
$$

This implies that source $i$ would have to reduce its emissions with two units if source $s$ increases its emissions by one unit. It is obvious that in this case the deposition at the one binding receptor would not change. The arguments for taking the ratio of the marginal costs in the optimum as exchange rates are:

- such an exchange rate takes into account the (weighted sum of) transfer coefficients that are binding in the optimum;

- the ratio reflects one of the Kuhn-Tucker conditions for the cost-minimum solution. 
Moreover, as for any fixed exchange rate, this has the advantage that trading is much simpler for the sources than trading with unknown trade ratios, where diffusion models have to be run after every single trade. This is expected to reduce transaction costs and stimulate trading and cost savings.

A disadvantage of the system is that the cost-minimum solution needs to be known to set the exchange rates. In the current negotiations on a new sulfur protocol, such information is available and cost-minimum solutions are provided to policy-makers to assist them at arriving at their decision (cf. UNECE, 1993). It is also clear, however, that countries might rather agree for political reasons on a solution that, although meeting a set of deposition targets, will not be at minimum costs. One can then ask the question why a central planner cannot use this knowledge on costs to devise a cost-sharing mechanism to agree on the cost minimum. The answer is that although such cost-sharing agreements have been proposed in the recent past (Klaassen and Jansen, 1989; Bergman et al., 1992), none of these were accepted, whereas the system of exchange rates described in this paper is being seriously discussed in the current negotiations (UNECE, 1992) on a new sulfur protocol.

First, an initial emission situation must be defined. Proportional reductions have been seen as the only fair solution in past agreements. If we take deposition targets seriously, an initial emission reduction can be defined as the least proportional reduction that does not violate the constraints. Referring to Figure 1, such a rule ensures that we start at a point on the feasible region $\mathrm{ABCD}$. The situation is shown in Figure 2 by point $F$.

An agreement on uniform proportional reduction moves us to point $F$ on the feasible region. This is not cost effective, as can be seen by comparing

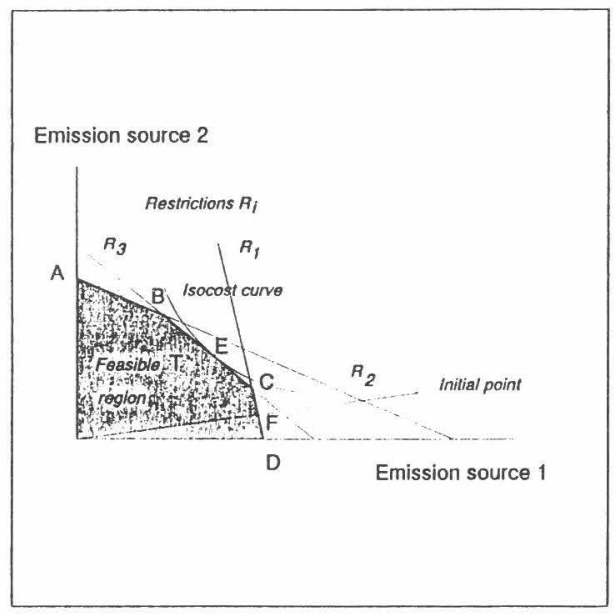

Figure 2. Trade at a fixed exchange rate. 
the isocost curve intersecting at $F$ and the least cost curve tangent to the feasible region at $E$.

Opening up for emission trading from point $\mathrm{F}$ may improve the cost effectiveness. But, when considering bilateral trades, instead of trading on a one-to-one basis, the potential impact of the deposition patterns will be taken into consideration by imposing "trade prices" equal to the exchange rates defined in Eq. (4). Let us assume that countries find the new emission agreement at $\mathrm{F}$ a burden and all try to lessen the costs by trading. Country 2 offers country 1 to decrease its emission by $v$ units in order to increase its own emissions with one unit as long as the payment it has to offer is less than what it saves by purifying less.

Expressing the solution (2) or the definition of the exchange rate (4) in the following way:

$$
c_{1}^{\prime}=v \cdot c_{2}^{\prime}
$$

where $v$ is the ratio of marginal costs in the optimal solution, the following conditions for profitable trades emerge:

(a) If $c_{1}^{\prime}>v c_{2}^{\prime}$, then country 1 profits by paying country 2 its marginal cost to purify more and to increase its own emissions.

(b) If $c_{1}^{\prime}<v c_{2}^{\prime}$, then country 2 profits by paying country 1 its marginal cost to purify more and to increase its own emissions.

Using the optimal exchange rate, $v$, for all trades means that in Figure 2 we are moving along a trade line through $F$ with a slope equal in absolute value to the exchange rate. If country 1 is to increase its purification, we move into the interior of the feasible region, but clearly the optimal point $E$ cannot be reached, since trading has to move along the dotted line (parallel to $R_{3}$ ). This contrasts to Krupnick et al. (1983) where trades are allowed to take place as long as the constraints are not violated and the exchange rate is not fixed beforehand.

At which point on the trade line will profitable trades be exhausted? Assuming the situation illustrated in Figure 2, we choose to see the situation from the point of view of the "high-cost" source 2 (without loss of generality). Assuming further that the "low-cost" source 1 offers to sell purification services to production costs at price $v$, the objective function for source 2 will be to maximize the total cost difference between its own saving and what it has to pay source 1 for purification, subject to the trading rule of the exchange rate:

$$
\operatorname{Max}_{e_{2}^{*}}\left(\int_{y_{2}=e_{2}^{p}}^{e_{2}^{*}} c_{2}^{\prime}\left(e_{2}^{0}-e_{2}\right) d e_{2}-\int_{y_{1}=e_{1}^{*}}^{e_{1}^{p}} c_{1}^{\prime}\left(e_{1}^{0}-e_{1}\right) d e_{1}\right)
$$

s. t. the trading rule

$$
\mathrm{e}_{2}^{*}-e_{2}^{P}=v\left(e_{1}^{P}-e_{1}^{*}\right)
$$


$e_{i}^{*}=$ emission after trade for country $i, i=1,2 ; e_{i}^{P}=$ negotiated protocol emission for country $i, i=1,2$.

The condition for the marginal trade is found by differentiating (6), taking into consideration the trading rule by substituting $e_{1}^{*}$ for $e_{2}^{*}$ in the lower integration limit in (6). The rule (5) re-emerges, but it does not represent point $E$, due to the trading rule which now has to be satisfied. The point reached will be $T$, which, in Figure 2, is inside the feasible region. Since the trading line is parallel with the target load restriction $R_{3}$ we have $c_{1}^{\prime}=v c_{2}^{\prime}$ at $T$, and no more profitable trades are possible. The difference between the isocost curves through $F$ and $T$ shows the gains from trade. The reason the trade within the exchange rate regime does not realize the optimal solution is that the exchange rate should only apply in the optimum, while the trading rule imposes the optimal rate for all intramarginal trades.

In general, the trade point $T$ does not have to be inside the feasible region. The low cost source in our example reduces emissions, but the high cost source increases emissions, and may increase beyond the feasible region. This outcome is illustrated in Figure 3 by point $T$. Hence, if it is of paramount importance to keep the trade solution within the feasible region, it seems that trade must take place within an institutional framework, checking up on every trade for feasibility. If it is necessary to stay within the feasible region, restricting the traded volumes (while maintaining the fixed exchange rate) would be sufficient to ensure that deposition targets are met. This would still prevent sources from attaining the cost minimum. The only way to solve this would be to return to the pollution offset trading à la Krupnick et al. (1983) which leaves determination of exchange rates to the sources as long as deposition targets are not violated. Whether violation of deposition targets has to be avoided at

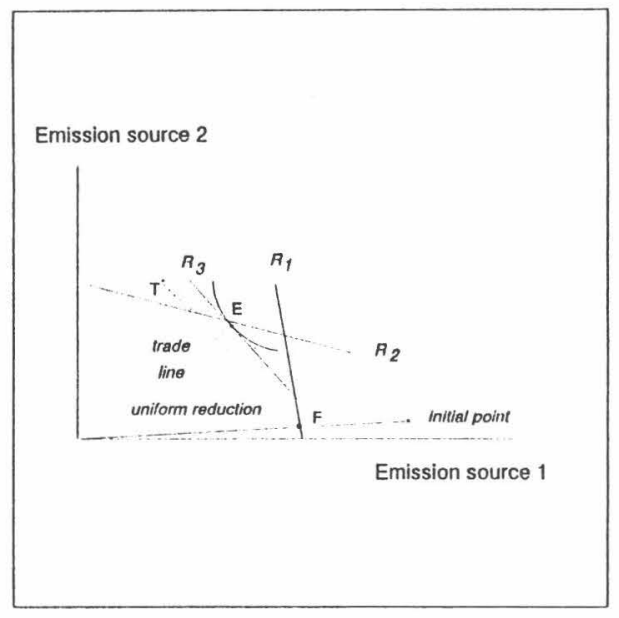

Fig. 3. Trade solution outside feasible region. 
every single trade is basically a political trade-off. Recent changes in the USA suggest that fixed trade ratios, such as the one-to-one trading allowed since the 1990 Clean Air Act amendments for sulfur, might well be politically feasible (Kete, 1992).

\section{Method and Data}

\subsection{THE MODEL APPLIED}

The method developed to simulate bilateral, sequential trading using trade ratios as introduced above makes use of an adapted version of the optimization module in the RAINS (Regional Acidification INformation and Simulation) model (Alcamo et al., 1990). The model has the theoretical structure of Eq. (1).

The cost functions of emission reductions, corresponding to Eq. (1), are expressed as piecewise linear curves denoting cost-minimal combinations of measures to achieve certain levels of national total emissions within each country (see Figure 4). The marginal costs are the slope of the total cost curve in each segment. $r_{i, s}$ is the purification in region $i$ in segment $s$. The amount purified in each of the segments $(s)$ is limited:

$$
0 \leq r_{i, s} \leq r_{i, s}^{\max }, \quad i=1, \ldots, 38, \quad s=1, \ldots, S .
$$

The RAINS model simulates the flow of acidifying pollutants (sulfur and nitrogen) from source regions in Europe to environmental receptors. The current model (version 6.0) covers 38 source regions in Europe: 26 countries, 7 regions in the former USSR and 5 sea regions (ship emissions). Enissions can be controlled in 36 regions. Analysis of deposition is performed

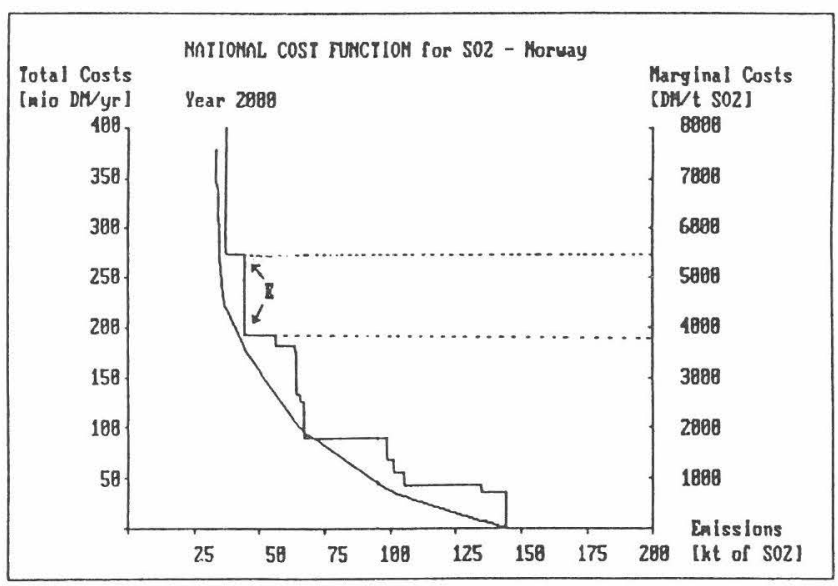

Fig. 4. Cost function. 
for 547 land-based receptor sites with a regular grid size of $150 \times 150 \mathrm{~km}$. For this study we limited the attention to sulfur dioxide emissions and sulfur deposition in line with current negotiations.

The optimization part of the RAINS model formulates possible strategies to minimize the costs of achieving deposition targets at certain receptors as a linear optimization problem (LP) that can be solved with LP packages (Amann, 1992; Batterman and Amann, 1991). The cost-effective solution requires that the total costs of emission reductions be minimized, subject to the constraint that the desired depositions are met at every receptor (see Eq. 1).

The piecewise linear cost function affects the practical definition of the exchange rate, which is the ratio of the marginal costs of the optimum. Due to the nature of linear optimization, the optimal status of most variables of an optimization problem will lie exactly at the corner points of the solution space, on the intersections of the linear cost function segments (e.g., point $E$ in Figure 4). For these points, however, a unique definition of marginal costs does not exist (for point $E$, marginal costs are either 3900 or $5500 \mathrm{DM} /$ ton $\mathrm{SO}_{2}$ ). The marginal costs for increasing emissions differ from the marginal costs for decreasing emissions. For this reason the simulation uses the higher marginal costs (the additional costs of further reducing emissions represented by the next step of the cost curve) by default. This also avoids problems with marginal costs of zero, for which the definition of the exchange rate is not applicable.

\subsection{THE METHOD TO SIMULATE BILATERAL TRADING}

\subsubsection{Introduction}

Until recently, many model studies simply assumed that the potential cost savings of emission trading would be identical to the results of optimization procedures; in other words, a perfectly working, competitive market where emission permits are simultaneously traded was assumed. Practice, as well as recent model studies (Atkinson and Tietenberg, 1991; Tietenberg, 1990), suggest that in reality trading takes place bilaterally and sequentially. With such restrictions, trading is not expected to capture the complete cost savings possible according to any LP cost minimisation procedure (compare Atkinson and Tietenberg, 1991). The trading algorithm presented here describes a process of repeated bilateral trading, subject to an offset or exchange rate for every possible combination of bilateral trades.

Figure 5 depicts a flow diagram of the trading algorithm. The diagram shows that the procedure consists of the following steps:

1. Creation of a matrix of potential cost savings from each potential bilateral trade. 


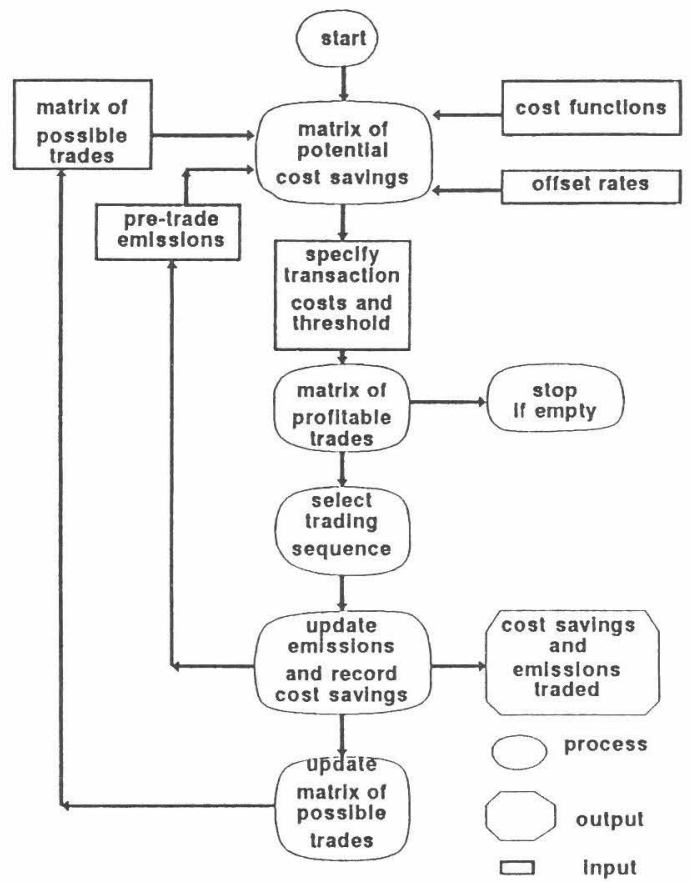

Fig. 5. Flow diagram of bilateral trading.

2. Specification of transaction costs and determination of threshold level, below which trades will not take place.

3. Selection of the trading sequence, taking the most profitable one first.

4. Updating of emissions after implementation of the selected trade and recording cost savings.

5. Updating of the matrix of possible trades, accounting for the trades that took place (return to step 1).

Regarding the creation of the cost-saving matrix, one should realize that cost functions estimated with the RAINS model are piecewise linear. As a result, RAINS does not work by equalizing marginal costs, but sorts and ranks elements of two (or more) cost functions according to their marginal costs (in ascending order). If an exchange rate is introduced, the determination of the cost-optimal bilateral combination of emission reductions can be performed in a similar way.

The two conditions for an optimum solution for each bilateral trade are condition (5) and the trade rule in (6), stating that the emission increase by source 2 should equal the emission decrease of source 2 multiplied by the exchange rate. Alternatively, the trade rule can be written as:

$$
e_{1}^{*}+e_{2}^{*} / v=e_{1}^{P}+e_{2}^{P} / v
$$


Since emissions have different impacts on the receptors a simple summation of emissions has little meaning. In order to get the emissions on the same receptor-oriented unit of measurement, emissions from source two (arbitrary choice) are weighted with the exchange rate. On the left-hand side we have the emissions after trade, while on the right-hand side we have the negotiated emissions, and on both sides the emissions are made comparable by weighting. We see clearly that it is only for the case of the exchange rate being 1 that pre-trade emission levels equal post-trade in tons.

Eqs. (5) and (8) have two unknowns, the post-trade emissions. For each pair of countries, $n \times(n-1) / 2=630$, we can find the solutions and create a matrix of cost savings of all possible trades.

In emission trading practice in the USA it can be observed that transactions costs frequently prohibit trading. Transactions costs are estimated at 10-30\% of the costs savings (Dwyer, 1991). Building in transaction costs (Step 2 in Figure 5) thus gives a more realistic picture of the potential cost savings. The algorithm allows specification of a (exogenous) level of transaction costs for each trade. If cost savings of a potential bilateral trade are below the threshold, the trade is not profitable and skipped from further selection.

After calculating the matrix of cost savings of all possible (and profitable) trades the sequence of trading is determined. Currently, the algorithm ranks all possible trades according to their cost savings and selects the one with the highest cost savings. Cost savings are defined as the difference between the total cost increase of the emission permit selling sources and the total cost decrease of the emission increasing source, between the pre-trade emission level (of every round) and the post-trade emission level. This is an optimistic assumption, assuming perfect information and coordination of the selection of traders. An alternative assumption, currently not implemented, would be that the selection of trade takes place at random. This is due to the imperfect information of traders and due to the competition between countries to get that trade accepted that is best for these two individual trade partners and not necessarily the best in terms of highest overall cost savings. When selecting the trade, the model does not explicitly check if the deposition targets are violated or not.

Updating the emission matrix and the matrix of possible trades is the final step.

Upon completion of the trade(s), the following steps are implemented:

1. Update the (pre-trade) emission vector, accounting for the trade(s) that took place.

2. Record the cost savings of the trade (compared to the pre-trade situation) in a file.

Finally, the matrix of possible trades is updated. Sources that have already traded are allowed to trade again, but not with the same partner: the cells of 
the cost-savings matrix corresponding to the trade between the two regions concluding the trade are skipped, and the cost savings of all the other trade relationships of these two countries are recalculated with the new emission levels.

\subsection{DATA ON COSTS AND ATMOSPHERIC TRANSPORT}

The RAINS model contains a sub-module to assess the feasibility and costs of alternative emission abatement technologies. The evaluation is based on internationally reported performance and cost data of control devices (Amann and Kornai, 1987). Cost estimates for specific technologies are extrapolated by the model to reflect country-specific conditions such as operating hours, boiler size, and fuel price. The following technical options are available:

1. Use of low sulfur fuels and fuel desulfurisation. This pertains to the use of fuels with a reduced sulfur content, such as fuels with a lower natural sulfur content or fuels that have undergone a desulfurisation process. For low sulfur hard coal, the sulfur content is set at $1 \%$. Desulfurisation of gas oil and diesel oil can reduce the sulfur content in two steps: down to $0.3 \%$ and down to $0.15 \%$. The desulfurisation of heavy fuel oil is assumed to be possible down to a level of $1 \%$.

2. Desulfurisation of flue gases during or after combustion. This set of measures requires investments at the plant site. Three techniques are considered: desulfurisation during combustion with removal efficiencies of $50 \%$ at relatively low costs, flue gas desulfurisation with a removal efficiency of $95 \%$ at moderate costs, and the use of advanced flue gas purification with emission reduction of $98 \%$ at high costs.

Not all abatement technologies are applicable for all fuel types and energy sectors. Moreover, a distinction is made between new and existing plants to account for the additional costs of retrofitting existing plants.

For the optimization, RAINS creates "national cost functions" for controlling emissions. National circumstances (such as sulfur content and operating hours) result in variations in the costs for applying the same technology in different countries in Europe. Another difference is the structural variation of energy systems, especially in the amount and structure of energy use, which determines the potential for application of individual control options. One way to combine these factors is to compile national cost functions. These functions display the lowest costs for achieving various emission levels by applying the cost optimal combination of abatement options. The cost curves used in this paper are based on official energy use projections for the year 2000 as published by the International Energy Agency.

Source-receptor transfer coefficients, which relate (country) emissions in the diffusion model to deposition at receptor points (for each grid), are based on the acid deposition model developed within the European Monitoring and 
Evaluation Program (EMEP) (Iversen et al., 1991). The model calculates transboundary fluxes of oxidized sulfur and nitrogen as well as reduced nitrogen (ammonia and its product ammonium). For the trade simulations presented in this paper, EMEP model results have been applied that reflect the meteorological average of the years 1985, 1987, 1988, 1989 and 1990.

\section{Results of the Trade Simulation}

\subsection{SCENARIO SETTING}

Current negotiations on the new sulfur Protocol (Amann et al., 1992) focus on sulfur deposition targets. Provisional (interim) sulfur deposition targets were proposed by ten countries. Recent discussion centered on the original target loads (as of December 1991) being increased uniformly by 10, 20, 30 or $40 \%$. For the purpose of this study, the original targets loads submitted by ten countries, uniformly increased by $40 \%$, have been selected as the reference targets (see Figure 6).

This section examines the cost-effectiveness and environmental impacts of the following instruments (or scenarios) for achieving the target loads:

1. a cost-minimum allocation of emission reduction measures (based on optimization);

2. a uniform percentage reduction of emissions for all countries;

3. emission trading with an offset rate of one;

4. emission trading with an exchange rate equal to the marginal costs in the optimum;

5. as 4 , but restricting trade to neighboring countries.

The allocation of reductions in Scenario 2 is steered by one "binding" receptor located in the United Kingdom. To meet the target load of this receptor, emissions have to be reduced by $84 \%$ compared to their 1980 levels. To create a "flat-rate" scenario, this $84 \%$ reduction was applied to all countries, where technically feasible. In those cases where such reductions were not considered achievable, the maximum technically feasible reductions were assumed. Since the extent of emission reduction is mainly steered by the "flat-rate" criterion, emission reductions in most countries are much higher than necessary to maintain target loads. Consequently, deposition is well below target loads at almost all receptor sites in Europe.

The emission trading schemes (Scenarios 3, 4 and 5) simulate bilateral, sequential trading. The trading scheme with an offset rate of one allows the exchange of emission reduction commitments on a one-to-one basis. Consequently, emissions are constant, though depositions obviously change. The second scheme (Scenario 4) has a different ratio for each particular trade. The last scheme applies the same exchange rate as Scenario 4 but restricts trading to neighboring countries (Førsund, 1992b). Neighbors are broadly 


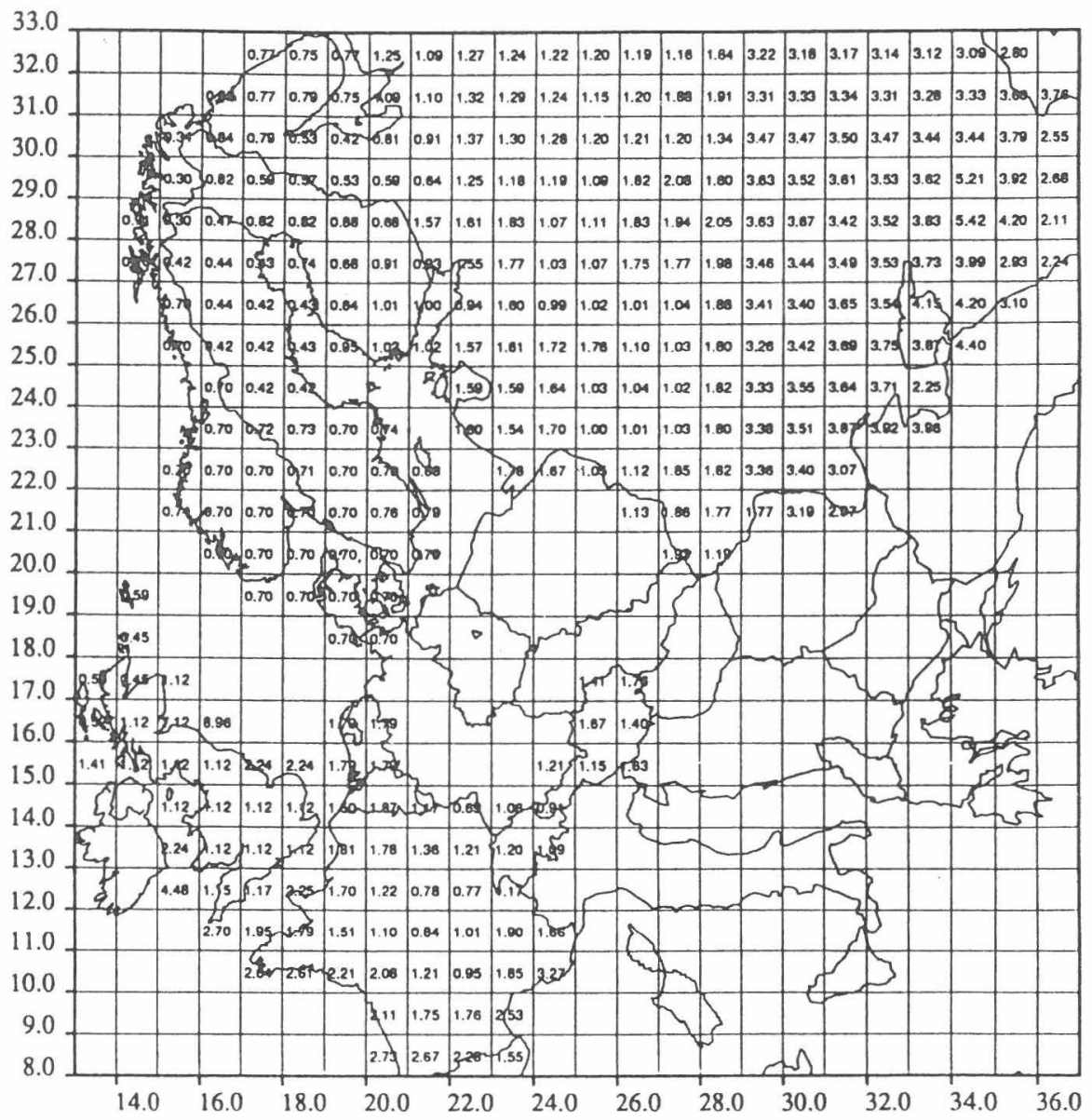

Figure 6. Target loads used in this paper ( $\left.\mathrm{g} \mathrm{S} / \mathrm{m}^{2} / \mathrm{yr}\right)$.

defined and also include countries that are divided by a sea (for example Poland and Norway).

In principle, emission trading can start from any initial distribution of emission reduction commitments. In this example, both emission trading schemes start from the $84 \%$ emission reduction target of Scenario 2. This has the advantage that initially the target loads are not violated and, therefore, it allows an analyis of whether or not emission trading results in violation of the targets.

\subsection{COST-EFFECTIVENESS AND ENVIRONMENTAL IMPACTS OF EMISSION TRADING SCENARIOS}

Table I displays the major results of the various scenarios in terms of their 
Table I. Comparison of instruments

\begin{tabular}{|c|c|c|c|c|c|}
\hline & \multicolumn{5}{|l|}{ Scenario } \\
\hline & 1 & 2 & 3 & 4 & 5 \\
\hline Scenario: & $\begin{array}{l}\text { Cost } \\
\text { minimum }\end{array}$ & $\begin{array}{l}\text { Uniform } \\
\% \\
\text { cutback }\end{array}$ & $\begin{array}{l}\text { Emission } \\
\text { trading } \\
\text { one-to-one }\end{array}$ & $\begin{array}{l}\text { Emission } \\
\text { trading } \\
\text { exchange } \\
\text { rate }\end{array}$ & $\begin{array}{l}\text { Emission } \\
\text { trading } \\
\text { neighbors } \\
\text { only }\end{array}$ \\
\hline $\begin{array}{l}\text { Annual costs } \\
\text { (mio DM) }\end{array}$ & 31200 & 63750 & 53267 & 44608 & 49639 \\
\hline $\begin{array}{l}\text { Annual costs } \\
\text { (as \% of uniform } \\
\text { cutback) }\end{array}$ & 49 & 100 & 84 & 70 & 78 \\
\hline $\begin{array}{l}\text { Emissions } \\
\qquad(\mathrm{kt} \mathrm{SO} \\
2)\end{array}$ & 26524 & 11760 & 11760 & 19727 & 16084 \\
\hline $\begin{array}{l}\text { Excess over target } \\
\text { loads (\% of } \\
\text { ecosystems) }\end{array}$ & 0.0 & 0.0 & 0.0 & 0.0 & 0.0 \\
\hline $\begin{array}{c}\text { Ecosystems protected } \\
\text { (\% of ecosystem) }\end{array}$ & 77 & 90 & 90 & 87 & 88 \\
\hline
\end{tabular}

emission control costs, the total remaining emissions and the violation of target loads. The Table shows that Scenario 1 (optimized allocation) is the most cost-effective means to achieve the target loads. Costs of a uniform percent reduction (Scenario 2) are twice as high as in Scenario 1. Starting from Scenario 2 , both emission trading schemes result in cost savings over the uniform reduction. However, trading on a one-to-one basis (Scenario 3) reduces costs by $16 \%$ (10 thousand millions DM/year), whereas trading using the exchange rates (based on the ratios of the marginal costs in the optimum, (Scenario 4) leads to cost savings of 30 percent over the uniform cut-back (Scenario 2) but does not attain the cost minimum (Scenario 1). Restricting trades to neighboring countries (Scenario 5) limits the costs savings to 22 percent. At the same time, environmental impacts are different for each scenario. Target loads are not violated, per definition, in Scenarios 1 and 2, and by keeping the very low initial level of emissions constant, one-to-one trading also does not result in exceeding target loads (at least in this particular case). The cost savings of Scenario 4 and 5 (exchange-rate trading) are obtained by a substantial increase in emissions. Still, this increase does not result in the exceeding of target loads after trading due to the very low pre-trade level of emissions.

Table I also shows that emissions remaining after the uniform cut-back (Scenario 2) are much lower than in Scenario 1 (cost minimum). Due to the flat rate requirement, emissions also have to be reduced in places where it is 
not necessary to meet the deposition targets. Since Scenario 2 is taken as the starting point for trading, Scenario 3 (one-to-one trading) keeps the total European emissions constant at this level, but achieves cost savings by equalizing marginal costs for all emitters. Since the very low pre-trade emissions result in a strong overfulfillment of the target loads, the rearrangement of reduction measures introduced by emission trading does not, in this case, violate target loads.

The exchange-rate trading (Scenario 4) results in a considerable increase in emissions, from $11760 \mathrm{kt}$ to $19727 \mathrm{kt}$. Consequently, costs are much lower than with the uniform cut-back. In spite of this increase in emissions, target loads are not violated. Again, this is due to the fact that initial (pre-trade) emissions are very low. Consequently, deposition at all but one of the receptors is much lower than the target loads. Hence, if trading starts from this very low initial level, deposition at most receptors can be raised without exceeding the target loads. When exchange-rate trading is restricted to neighbors (Scenario 5) the increase in emissions due to trading is more limited (increase to $16084 \mathrm{kton}$ ). This, and the fact that only neighbors trade, limits but does not eliminate the chance of exceeding target loads.

The environmental impacts depend on the actual depositions of sulfur, and positive impacts exist even if the deposition is below the targets. One way to express this is to take a look at the average percentage of ecosystems in Europe that are exposed to levels of sulfur deposition below so-called critical loads, i.e., loads below which no damage is expected. The last row in Table I shows that, although the exceedance of target loads does not differ between the scenarios, the percentage of ecosystems protected does. Although oneto-one trading (as in the USA) does not change the percentage of ecosystems protected compared to the uniform cutback (in both cases $90 \%$ ) exchangerate trading would only result in $87 \%$ protection and the cost minimum only in $77 \%$ protection. Both exchange-rate trading as well as the cost minimum ignore benefits of reducing deposition below target loads.

\subsection{A CLOSER LOOK AT EXCHANGE-RATE TRADING}

Whereas in Scenario 3 a uniform exchange rate of one was selected, Scenario 4 explores the scope for non-uniform rates. Since exchange or offset rates are instruments to determine the profitability and, thereby, the economic potential for individual trades, a selection of appropriate rates could steer the trading process into certain desired directions.

To steer the trading process in this direction, one of the Kuhn-Tucker conditions for the cost minimum (Eq. (6) in Section 2) is used to determine the exchange rate of emission trading between two countries. Thereby, the offset rate is set equal to the ratio of the marginal costs of emission reductions in the optimum: $v=c_{1}^{\prime} / c_{2}^{\prime}$. 
For example, marginal costs for country 1 of $2000 \mathrm{DM} / \mathrm{t} \mathrm{SO}_{2}$ and for country 2 of $1000 \mathrm{DM} / \mathrm{t} \mathrm{SO}$ result in an exchange rate of 2 :

$$
\frac{c_{1}^{\prime}}{c_{1}^{\prime}}=\frac{2000}{1000}=\frac{2}{1}=2
$$

This implies that if source 1 increases emissions with one unit, source 2 can reduce its emissions with 2 units. Since marginal costs in the optimum generally differ among countries, exchange rates for the bilateral trades will also be different for each trade combination.

Table II shows the trades that are expected to be implemented for this scenario. The exchange rate differs among the implemented trades between 0.03 (Trade 6) and 11.12 (Trade 21). The first trade is expected to take place between Turkey and France. Due to Turkey's rapid economic development, the marginal costs of the pre-trade initial status (an $84 \%$ emission reduction compared to 1980) are extremely high. The optimal solution, however, prescribes no emission reductions for Turkey since its emissions do not deposit on areas for which target loads are binding. Consequently, the marginal costs of the optimal solution are zero. The resulting exchange rate with France of 0.08 (French marginal costs of the optimum are only $8 \%$ of the marginal costs in Turkey) allows Turkey to increase its emissions by $1912 \mathrm{kt}$ up to the unabated level (i.e., $3254 \mathrm{kt}$ of $\mathrm{SO}_{2}$ ), whereas France would reduce its emissions by $1912 \times 0.075=144 \mathrm{kt}$. This saves Turkey abatement costs of 5.0 thousand millions DM/yr, while costs in France increase by 622 million $\mathrm{DM} / \mathrm{yr}$. The net cost savings of this trade are 4.4 thousand millions DM/year.

After implementation of the first trade, pre-trade emissions change and the potential cost savings of all remaining bilateral trades with either France or Turkey involved are calculated again. The trade with the highest cost saving is implemented. This procedure is repeated until no trade with cost savings above a certain threshold (in the example, 0.1 million DM/year) is left. Table II shows that 35 trades would be implemented under the exchange rate regime. The total cost savings per year would amount to 19.0 thousand millions $\mathrm{DM} /$ year. The gains from the first ten trades add up to nearly $90 \%$ of the total cost savings. As can be observed, a number of countries (e.g., Turkey, France, remaining part of the former USSR, Poland, Kola Peninsula) would trade with several partners.

If the exchange-rate trading would be restricted to neighboring countries, cost savings would be somewhat smaller. The trading pattern would also be different from Table II. The most profitable trade now would be struck between Turkey and Ukraine, saving nearly 2 thousand millions DM per year. France now trades with Spain, Italy, the Netherlands, Switzerland and Luxembourg, reducing its emissions, therefore allowing these countries to increase emissions. France is a country with high marginal costs in the optimal solution and one of the twelve binding target loads is located in France. 
Table I indicates the extent to which exchange-rate trading is able to approach the cost-minimum solution. With exchange-rate trading costs are 44608 million DM/year, whereas the optimal cost level is only 31200 million $\mathrm{DM} /$ year. After trading, 22 countries (out of 33) have marginal costs that are equal to the marginal costs in the optimum. This implies that trades between these 22 countries would not result in cost savings, since their marginal cost ratios equal the exchange rates. For all other countries, marginal costs in the pre-trade situation exceed the marginal costs of the optimum. This indicates that if one trade between these countries were to take place, one country would move towards the optimum but the other would move further away. The results further suggest that of the other trades still possible, the cost savings are smaller than the threshold of 0.1 million DM/year. Although 22 countries have marginal costs equal to the optimum marginal costs, only six countries (Belgium, Hungary, Luxembourg, Rumania, Ukraine and Moldavia) actually reach the same emission levels. That is, the first mentioned of these 22 countries end up in a different part of the same segment of the cost curve. One example is France, where the optimum ( $402 \mathrm{kt} \mathrm{SO}_{2}$ ) is at the upper end, and the pretrade emission $\left(253 \mathrm{kt} \mathrm{SO}_{2}\right.$ ) is at the lower end of the same segment (of 9506 $\mathrm{DM} /$ ton $\mathrm{SO}_{2}$ ) of the cost curve. This affirms that the result of exchange-rate trading depends on the pre-trade emission levels.

Table I also shows that emissions will increase after trading from 11760 to $19727 \mathrm{kt}$. The emissions are still lower than necessary $\left(26654 \mathrm{kt} \mathrm{SO}_{2}\right)$ to meet the cost minimum. As a result, pollution control costs, although below the initial level of 63.7 thousand millions DM/year, are (with 44.6 thousand millions DM/year) still above the cost minimum.

Several factors are responsible for the non-attainment of the optimal solution. First, the exchange rate is based only on one condition for the optimum solution. It ignores the fact that deposition has to be below the standard, and hence the mathematical formulations of both cost minimization and exchange-rate trading are not identical. Second, the concept of marginal costs is ambiguous for piecewise linear cost curves. In the optimum solution, the stepwise cost function sometimes allows for two optimal marginal costs due to the piecewise linear cost functions (compare Figure 4). The exchange rate, however, is only based on one of them. Finally, the post-trade situation is not independent of the initial pre-trade emission level, since the exchange rate applies to all (intramarginal) trades, and thus does not rule out that exchange-rate trading ends at an interior solution.

\subsection{THE SENSITIVITY OF THE TRADE SIMULATIONS}

The results discussed above depend on the specific situation assumed for these scenarios and may be sensitive to changes in: pre-trade emission levels, transaction costs, availability of information to the traders (perfect or imperfect) 
Table II. Trades implemented with exchange-rate trading

\begin{tabular}{|c|c|c|c|c|c|c|c|c|}
\hline Trade & $\begin{array}{l}\text { Buyer of } \\
\text { emission } \\
\text { permits }\end{array}$ & $\begin{array}{l}\text { Amount } \\
(\mathrm{kt} \mathrm{SO})_{2}\end{array}$ & $\begin{array}{l}\text { Remain. } \\
\text { emission } \\
(\mathrm{kt} \mathrm{SO})_{2}\end{array}$ & $\begin{array}{l}\text { Seller of } \\
\text { permits }\end{array}$ & $\begin{array}{l}\text { Amount } \\
(\mathrm{kt} \mathrm{SO})_{2}\end{array}$ & $\begin{array}{l}\text { Remain. } \\
\text { emission } \\
\left(\mathrm{kt} \mathrm{SO}_{2}\right)\end{array}$ & $\begin{array}{l}\text { Exchange } \\
\text { rate }\end{array}$ & $\begin{array}{l}\text { Cost Saving } \\
\text { (mio DM/yr) }\end{array}$ \\
\hline 1 & Turkey & 1912 & 3254 & France & -144 & 414 & 0.08 & 4386 \\
\hline 2 & Rem CIS & 2827 & 3978 & FRG-E & -414 & 384 & 0.15 & 2437 \\
\hline 3 & Bulgaria & 1303 & 1540 & France & -93 & 321 & 0.07 & 1579 \\
\hline 4 & Poland & 166 & 750 & Baltic & -64 & 138 & 0.38 & 1499 \\
\hline 5 & Spain & 2568 & 3065 & France & -67 & 254 & 0.03 & 1401 \\
\hline 6 & Yugoslavia & 709 & 1030 & FRG-W & -124 & 379 & 0.17 & 1306 \\
\hline 7 & Rumania & 1087 & 1401 & Yugoslavia & -560 & 468 & 0.52 & 1285 \\
\hline 8 & Kola & 350 & 461 & Rumania & -856 & 544 & 2.45 & 951 \\
\hline 9 & CSFR & 58 & 766 & Kola-Karelia & -81 & 380 & 1.40 & 829 \\
\hline 10 & Sweden & 210 & 304 & Turkey & -362 & 2891 & 1.73 & 778 \\
\hline 11 & Greece & 249 & 338 & Spain & -792 & 2272 & 3.18 & 641 \\
\hline 12 & Hungary & 30 & 610 & Kola-Karelia & -61 & 319 & 2.06 & 365 \\
\hline 13 & Austria & 45 & 108 & Italy & -48 & 566 & 1.07 & 318 \\
\hline 14 & Portugal & 274 & 316 & Bulgaria & -350 & 1188 & 1.28 & 280 \\
\hline 15 & Norway & 79 & 112 & United Kingdom & -43 & 730 & 0.55 & 245 \\
\hline 16 & Ireland & 107 & 157 & Denmark & -34 & 37 & 0.32 & 213 \\
\hline 17 & Petersburg & 86 & 182 & Poland & -34 & 716 & 0.40 & 158 \\
\hline 18 & Albania & 103 & 145 & Ukraine & -75 & 996 & 0.73 & 142 \\
\hline
\end{tabular}


Table II. (Continued)

\begin{tabular}{|c|c|c|c|c|c|c|c|c|}
\hline Trade & $\begin{array}{l}\text { Buyer of } \\
\text { emission } \\
\text { permits }\end{array}$ & $\begin{array}{l}\text { Amount } \\
\left.(\mathrm{kt} \mathrm{SO})_{2}\right)\end{array}$ & $\begin{array}{l}\text { Remain. } \\
\text { emission } \\
\left(\mathrm{kt} \mathrm{SO}_{2}\right)\end{array}$ & $\begin{array}{l}\text { Seller of } \\
\text { permits }\end{array}$ & $\begin{array}{l}\text { Amount } \\
(\mathrm{kt} \mathrm{SO})\end{array}$ & $\begin{array}{l}\text { Remain. } \\
\text { emission } \\
\left(\mathrm{kt} \mathrm{SO}_{2}\right)\end{array}$ & $\begin{array}{l}\text { Exchange } \\
\text { rate }\end{array}$ & $\begin{array}{l}\text { Cost Saving } \\
\text { (mio DM/yr) }\end{array}$ \\
\hline 19 & Finland & 132 & 223 & Turkey & -520 & 2370 & 3.96 & 118 \\
\hline 20 & Switzerland & 2 & 45 & Byelorussia & -23 & 146 & 9.84 & 63 \\
\hline 21 & Luxembourg & 5 & 7 & Rumania & -50 & 493 & 11.12 & 35 \\
\hline 22 & Rem. CIS & 227 & 4205 & Greece & -140 & 197 & 0.62 & 25 \\
\hline 23 & Belgium & 6 & 137 & Bulgaria & -26 & 1162 & 4.74 & 18 \\
\hline 24 & Rem. CIS & 186 & 4391 & Turkey & -128 & 2242 & 0.69 & 18 \\
\hline 25 & Rem. CIS & 147 & 4538 & Portugal & -84 & 233 & 0.57 & 12 \\
\hline 26 & Rem. CIS & 111 & 4649 & Albania & -76 & 69 & 0.68 & 11 \\
\hline 27 & Rem. CIS & 29 & 4678 & Switzerland & -2 & 44 & 0.06 & 7 \\
\hline 28 & Rem. CIS & 22 & 4700 & Hungary & -3 & 607 & 0.12 & 5 \\
\hline 29 & Rem. CIS & 32 & 4733 & Netherlands & -5 & 68 & 0.16 & 5 \\
\hline 30 & Rem. CIS & 21 & 4754 & Luxembourg & -1 & 5 & 0.05 & 5 \\
\hline 31 & Rem. CIS & 15 & 4769 & Norway & -9 & 103 & 0.57 & 4 \\
\hline 32 & Rem. CIS & 67 & 4836 & Ireland & -38 & 120 & 0.57 & 1 \\
\hline 33 & Rem. CIS & 146 & 4981 & Austria & -29 & 79 & 0.20 & 1 \\
\hline 34 & Rem. CIS & 7 & 4988 & Bulgaria & -5 & 1157 & 0.73 & 1 \\
\hline 35 & Rem. CIS & 3 & 4991 & Moldavia & -2 & 77 & 0.62 & 1 \\
\hline
\end{tabular}


on the potential cost savings of each trade, information on cost functions available to the environmental agency determining the exchange rate or offsetrates, and assumptions made on the behavior of the trading partners.

Table III explores the sensitivities introduced by changes in pre-trade emissions and transaction costs by analyzing a different starting point (starting from the optimum solution instead of the uniform $84 \%$ reduction), and by including transaction costs on the performance of emission trading with an exchange rate. Column (b) repeats the results of the cost-minimum solution and column (c) gives the results for exchange-rate trading if this trading starts from the uniform cutback. It can be seen that if exchange-rate trading started from the optimum (column d) it would stay close to the optimum (column b). Two trades take place that only marginally change emissions. The first trade allows Turkey to reduce emissions and the Baltic region to increase. These trades are caused by the definition problem of marginal costs in the optimum mentioned before. The traded amounts, however, are limited. As a result, cost savings are very small and the target loads are not exceeded.

Table III. Sensitivity of exchange-rate trading

\begin{tabular}{lllll}
\hline (a) & (b) & (c) & (d) & (e) \\
\hline Scenario: & $\begin{array}{l}\text { Cost } \\
\text { minimum }\end{array}$ & $\begin{array}{l}\text { Emission } \\
\text { trading } \\
\text { exchange rate }\end{array}$ & $\begin{array}{l}\text { Pre-trade } \\
\text { emissions } \\
\text { of optimum }\end{array}$ & $\begin{array}{l}\text { Transaction costs } \\
(50 \text { mio DM/ } \\
\text { trade per year) }\end{array}$ \\
\hline $\begin{array}{c}\text { Annual costs } \\
\text { (Mio DM) }\end{array}$ & 31200 & 44608 & 31195 & 44750 \\
$\begin{array}{c}\text { Annual costs } \\
\text { (as \% of cost } \\
\text { minimum) }\end{array}$ & 100 & 143 & 100 & 143 \\
$\begin{array}{c}\text { Emissions } \\
\left(\mathrm{kt} \mathrm{SO} \mathrm{SO}_{2}\right)\end{array}$ & 26524 & 19727 & 26537 & 19343 \\
\hline
\end{tabular}

The second example analyzes the potential influence of non-zero transaction costs (costs of finding a trading partner, agreeing upon a trade, getting a trade accepted) (column e). An assumed level of 50 million DM/year per trade (column e) would reduce the number of profitable trades to 19 (instead of 35) (as in column c), starting from a uniform $84 \%$ cutback. The pollution control costs would not differ significantly from the reference scenario (column c), but the distribution of emissions would change considerably (a number of trades would not take place). Still, the target loads are not violated. Again this is due to the fact that initial emissions are very low, over-satisfying targets at most receptors. It can be concluded that in this case the impact of transaction costs on cost savings is negligible.

Although exchange-rate trading does not result in the exceeding of target loads, at least not in the examples shown, simple one-to-one trading does, if 
one starts from the optimum emission level. Although overall European emissions are kept at the same level as before, their geographical distribution differs, resulting now in exceeding target loads for $2 \%$ to $95 \%$ of the ecosystems in the ten countries that submitted target loads.

Three other assumptions deserve discussion. First, the algorithm assumes perfect information: trades are implemented in descending order of their costsavings. Assuming imperfect information (random trading) might result in considerably lower cost savings than in the first case (see Atkinson and Tietenberg, 1991). This requires further analysis. Second, to set the exchange rate it is assumed that the environmental agency has perfect information about abatement costs when determining the optimal solution. It appears more realistic, however, to assume that this information is less than perfect, mainly because cost functions depend crucially on the underlying prediction of future energy consumption. Consequently, if the agency sets exchange rates on centrally perceived cost curves it might well be that countries trade on the basis of what they individually see as realistic cost functions. The results of emission trading will therefore differ from the expectations of the agency. As a result, the emission pattern (determining environmental impacts) will also be uncertain. Third, given initial emission and exchange rates, it is assumed that trading partners will try to minimize costs. Although this is a realistic assumption for firms operating on a competitive market, it is doubtful whether this is an adequate assumption for the behavior of countries in an international context (Kremeniouk, 1991). Countries might well place more emphasis on their environmental targets than on cost-effectiveness. Moreover, aspects of administrative practicality as well as political considerations are likely to play an important role (compare Opschoor and Vos, 1989).

\section{Conclusions and Discussion}

Emission trading offers an alternative approach for achieving cost-effective implementation of effect-oriented policy targets. The situation is complex when considering non-uniformly dispersed pollutants, where the location of the emission source is important. In theory, trading deposition (or ambient) permits or pollution-offset trading would fulfill the conditions for cost-minimal resource allocation. However, it is very difficult to design trade regimes that will lead the players to approach the optimal solution by themselves. This points to the need for a simpler design. One relatively simple system is to have national emission quotas, initially, and allow countries to trade according to a fixed exchange rate. From a number of formal conditions for the cost-minimum solution, the ratios of the marginal costs of abatement in the optimal solution are introduced into a new trading scheme as exchange rates for emission trading. Thereby, the transfer coefficients of those receptors that are binding in the optimum are taken into account. It is shown that, generally, because other necessary conditions for an optimum solution are neglected, this system 
will not achieve the optimal solution. In addition, such a trading system does not guarantee that environmental deposition constraints are not violated. But purification costs are reduced.

Based on the IIASA RAINS model, a routine has been developed to simulate bilateral, sequential emission trading for the specific situation of reducing $\mathrm{SO}_{2}$ emissions in Europe.

For a set of example target loads for the deposition, calculations identified the cost-minimal allocations of emission reductions and the required uniform reduction strategy to satisfy the selected target loads. Taking an $84 \%$ uniform reduction strategy as a starting point, emission trading simulations achieved cost savings. A one-to-one offset rate (keeping total European emissions constant) limits the potential cost savings to $16 \%$; deposition targets are not violated, since initial emissions allocation overfulfilled targets at many places. If an exchange rate, based on marginal costs, is applied to trading, total emissions increase considerably, thereby achieving more significant cost savings (30\%). Allowing only neighbors to trade limits cost savings and reduces the chance that deposition targets are violated but might be more politically acceptable. Again, due to the low level of pre-trade emissions, the specified target loads are not exceeded with both exchange-rate trading schemes.

The results of emission trading are sensitive to a number of assumptions, such as the pre-trade emission levels, the transaction costs, the availability of information on potential cost savings and assumptions made on the behavior of trading partners. Despite this sensitivity, the trading schemes explored in this paper offer possibilities for significant costs savings.

\section{Acknowledgements}

The authors appreciate the comments from Scott Atkinson, Andries Nentjes, Charles Paulsen and two anonymous reviewers, and the assistance from Eric Nævdal in computing the "neighbor" results. Funding from the Norwegian Ministry of the Environment is gratefully acknowledged.

\section{Notes}

1 Restrictions on lower and upper limits on emissions could be introduced for increased realism, as in Førsund (1992a), but we simplify here since assuming an interior solution for emission levels does not play any role for the trade problem dealt with.

\section{References}

Alcamo, J., L. Hordijk and R. Shaw, eds. (1990), The RAINS Model of Acidification, Kluwer Academic Publishers, Dordrecht/Boston/London.

Amann, M. (1992), Zur Effizienten Multinationalen Allokation von Emissionsminderungs- 
massnahmen zur Verringerung der Sauren Deposition - Anwendungsbeispiel Österreich, Dissertation, University of Karlsruhe, Karlsruhe, Germany.

Amann, M., I. Bertok, J. Cofala, G. Klaassen and W. Schöpp (1992), Strategies for Reducing Sulfur Dioxide Emissions in Europe, SR-92-8, International Institute for Applied Systems Analysis, Laxenburg, Austria.

Amann, M. and G. Kornai (1987), Cost Functions for Controlling $\mathrm{SO}_{2}$ Emissions in Europe, WP 87-065, International Institute for Applied Systems Analysis Laxenburg, Austria.

Atkinson, S. and T. H. Tietenberg (1991), 'Market Failure in Incentive Based Regulation: The Case of Emissions Trading', Journal of Environmental Economics and Management 21, 17-31.

Batterman, S. A. and M. Amann (1991), 'Targeted Acid Rain Strategies Including Uncertainty', Journal of Environmental Management 32, 57-72.

Baumol, W. and W. Oates (1988), The Theory of Environmental Policy, Cambridge University Press, Cambridge.

Bergman, L., H. Cesar and G. Klaassen (1992), 'Efficiency in Transboundary Pollution Abatement', in J. J. Krabbe and W. J. M. Heyman, eds., National Income and Nature: Externalities, Growth and Steady State, pp. 125-142, Kluwer Academic Publishers, Dordrecht/ Boston/London.

Borowski, A. R. and H. E. Ellis (1987), 'Summary of the Final Federal Emissions Trading Policy Statement', Journal of the Air Pollution Control Association 37(7), 798-800.

Derwent, R. G. (1990), Optimal Strategies for Sulfur Emission Control in Europe, Harwell Laboratory, Oxfordshire.

Dwyer J. (1991), California's Tradeable Emissions Policy and its Application to the Control of Greenhouse Gases, Paper presented at the OECD workshop "Tradeable Permits for Reducing Greenhouse Gases", June 26-27, 1991, OECD, Paris.

Førsund, F. R. (1992a), BAT and BATNEEC: An Analytical Interpretation, Memorandum no. 28, December, Department of Economics, University of Oslo.

Førsund, F. R. (1992b), Emission Trading, Paper presented at the UN/ECE Task Force on Economic Aspects of Abatement Strategies, Bilthoven, June 1-2, 1992.

Hahn, R. W. and G. Hester (1989), 'Where Did All the Markets Go? An Analysis of EPA's Emissions Trading Program', Yale Journal on Regulation 6(1), 109-153.

Hahn, R. W. (1989), 'Economic Prescriptions for Environmental Problems: How the Patient Followed the Doctor's Orders', Journal of Economic Perspectives 3(2), 95-114.

Iversen, T., N. E. Halvorsen, S. Mylona and H. Sandnes (1991), Calculated Budgets for Airborne Acidifying Components in Europe, 1985, 1987, 1988, 1989 and 1990, The Norwegian Meteorological Institute, Oslo.

Kete, N. (1992), 'The Acid Rain Control Allowance Trading System', in T. Jones and J. CorfeeMorlot, eds., Climate Change, Designing a Tradeable Permit System, pp. 78-108, OECD, Paris.

Klaassen, G. and H. Jansen (1989), Economic Principles for Allocating the Costs of Reducing Sulfur Emissions in Europe. EB.AIR/Ge.2/R.26 (Economic Commission for Europe), United Nations, Geneva.

Kremeniouk, R., ed. (1991), International Negotiation, Jossey-Bass, San Francisco.

Kruitwagen, S. (1992), Tradeable Permits for $\mathrm{SO}_{2}$ Emissions in Europe: A Pollution Offset Experiment, Wageningen Economic Papers (Faculty of Economics), Wageningen Agricultural University, Wageningen.

Krupnick, A. J., W. E. Oates and E. van de Verg (1983), 'On Marketable Air Pollution Permits: The Case for a System of Pollution Offsets', Journal of Environmental Economics and Management 10, 233-247.

McGartland, A. M. and W. E. Oates (1985), 'Marketable Permits for the Prevention of Environmental Deterioration', Journal of Environmental Economics and Management 12, 207-228. 
Montgomery, W. D. (1972), 'Markets in Licenses and Efficient Pollution Control Programs', Journal of Economic Theory 5, 395-418.

Opschoor, J. B. and H. B. Vos (1989), Economic Instruments for Environmental Protection, OECD, Paris.

Tietenberg, T. H. (1985), Emission Trading: An Exercise in Reforming Pollution Policy, Resources for the Future, Washington, D.C.

Tietenberg, T. H. (1990), 'Economic Instruments for Environmental Protection', Oxford Review of Economic Policy 6(1), 17-33.

UNECE (1992), Economic Aspects of Abatement Strategies. Progress Report by the Chairman of the Task Force, EB.AIR/WG5/R.36, United Nations, Geneva.

UNECE (1993), Integrated Assessment Modelling. Progress Report by the Chairman of the Task Force, EB.AIR/WG.5/R.38, United Nations, Geneva. 
